\title{
Evaporation waves in superheated dodecane
}

\author{
By J. R. SIMÕES-MOREIRA ${ }^{1}$ AND J. E. SHEPHER D ${ }^{2} \dagger$ \\ ${ }^{1}$ Departamento de Engenharia Mecânica, SISEA - Alternative Energy Systems Laboratory, \\ Escola Politécnica da USP, caixa postal 61548, São Paulo, SP, Brazil \\ e-mail: jrsimoes@usp.br \\ ${ }^{2}$ Graduate Aeronautical Laboratory, California Institute of Technology, Pasadena, \\ CA 91125 , USA \\ e-mail: jeshep@galcit.caltech.edu
}

(Received 3 February 1997 and in revised form 18 September 1998)

We have observed propagating adiabatic evaporation waves in superheated liquid dodecane, $\mathrm{C}_{12} \mathrm{H}_{26}$. Experiments were performed with a rapid decompression apparatus at initial temperatures of $180-300^{\circ} \mathrm{C}$. Saturated dodecane in a tube was suddenly depressurized by rupturing a diaphragm. Motion pictures and still photographic images, and pressure and temperature data were obtained during the evaporation event that followed depressurization. Usually, a front or wave of evaporation started at the liquid free surface and propagated into the undisturbed regions of the metastable liquid. The evaporation wave front moved with a steady mean velocity but the front itself was unstable and fluctuating in character. At low superheats, no waves were observed until a threshold superheat was exceeded. At moderate superheats, subsonic downstream states were observed. At higher superheats, the downstream flow was choked, corresponding to a Chapman-Jouguet condition. At the most extreme superheat tested, a vapour content of over $90 \%$ was estimated from the measured data, indicating a nearly complete evaporation wave. Our results are interpreted by modelling the evaporation wave as a discontinuity, or jump, between a superheated liquid state and a two-phase liquid-vapour downstream state. Reasonable agreement is found between the model and observations; however, there is a fundamental indeterminacy that prevents the prediction of the observed wave speeds.

\section{Introduction}

In certain situations, the pressure of a liquid may suddenly be reduced far below the saturation condition without immediate occurrence of boiling. As a result, the liquid becomes superheated or metastable. The superheat is characterized by the difference between the actual liquid temperature and the temperature of the saturated liquid at that pressure. Superheats of up to $200^{\circ} \mathrm{C}$ are possible. Following a brief incubation period, explosive evaporation results. Such steam or physical explosions are implicated (Reid 1976, 1983) in some types of industrial accidents.

Under specific conditions, described below, a superheated liquid will evaporate in a wave-like process; that is, the phase change process is confined to a discrete and observable zone, which moves into the undisturbed metastable liquid and a two-phase mixture is observed downstream of the wave front (Terner 1962; Grolmes \& Fauske 1974; Thompson et al. 1987; Hill 1991; Simões-Moreira 1994; Simões-Moreira \&

$\dagger$ Author to whom correspondence should be addressed. 
Shepherd 1994). The occurrence of the evaporation wave depends on several factors: the thermodynamic properties of the substance, the degree of superheat, the absence of activated nucleation sites, and the depressurization time scale. Evaporation waves have also been observed (Shepherd \& Sturtevant 1982; Frost \& Sturtevant 1986; Frost 1988; Nguyen, Furzeland \& Ijpelaar 1988) at a small scale within superheated droplets. Other terms used to designate the phenomenon are boiling discontinuities or boiling shocks (Labuntsov \& Avdeev 1981, 1982), boiling front propagation (Das, Bhat \& Arakeri 1987) and flash boiling.

The evaporation waves we are considering can be idealized as adiabatic phase transitions with the latent heat of vapourization supplied from the energy stored in the metastable liquid. The vapourization process is self-sustaining due to the superheated nature of the liquid. In this sense, evaporation waves are analogous to combustion fronts such as flames, in which the energy is stored in the chemical bonds of the reactants and the flame process is self-sustaining due to the metastable nature of a fuel-oxidizer mixture or molecular explosive. This analogy immediately suggests the possibility of analysing evaporation waves using control volume concepts and jump conditions, just as in the case of deflagrations and detonations. We have interpreted our experiments using this notion together with a realistic equation of state and two-phase flow models for the flow downstream of the wave front. An exposition of this simple model is given in $\S 2$. In $\S 5$, we propose an extension of this simple theory to include the effect of velocity slip in the two-phase flow downstream of the wave.

The simple model predicts, and large-superheat experiments confirm, that there is a maximum mass flux through an evaporation wave. In analogy with the simple theory of deflagration waves, the choked solution is called the Chapman-Jouguet (CJ) point. The CJ point is a unique solution to the jump conditions for which the downstream flow is sonic or choked in relation to the moving deflagration wave. Some previous researchers (Chaves 1984; Thompson et al. 1987) have focused on the CJ point as defining a unique evaporation wave speed. However, the pioneering study of Hill (Hill \& Sturtevant 1990; Hill 1991) demonstrated, and the present experiments confirm, that a range of evaporation wave speeds is possible depending on the pressure drop across the wave and the degree of superheat of the upstream liquid. These findings are in agreement with previous experimental results (Hill \& Sturtevant 1990; Hill 1991) and indicate that both subsonic and sonic solutions are possible, depending on the initial thermodynamic conditions and the fluid boundary conditions.

This paper reports results and analyses of experiments carried out with saturated dodecane at temperatures of $180-300^{\circ} \mathrm{C}$. The distinction of the present study is the systematic examination of the effect of superheat and reservoir pressure on evaporation wave characteristics, the use of a highly retrograde pure substance (dodecane) as the working fluid and consideration of velocity slip due to wall effects. The experimental setup is described in $\S 3$ and the results are given in $\S 4$. Our choice (Simões-Moreira, McCahan \& Shepherd 1993) of dodecane is related to the theoretical possibility of obtaining a complete evaporation wave due to its retrograde behaviour. A complete evaporation wave will have only the vapour phase in the downstream flow. The retrograde property is associated with molecular complexity and is macroscopically characterized by a positive slope of the vapour branch of the temperature-entropy saturation line. Therefore, a retrograde liquid can undergo complete evaporation in an isentropic expansion process, which is an impossibility for regular substances such as water. A discussion of this aspect of the experiments is given in $\S 6$. 


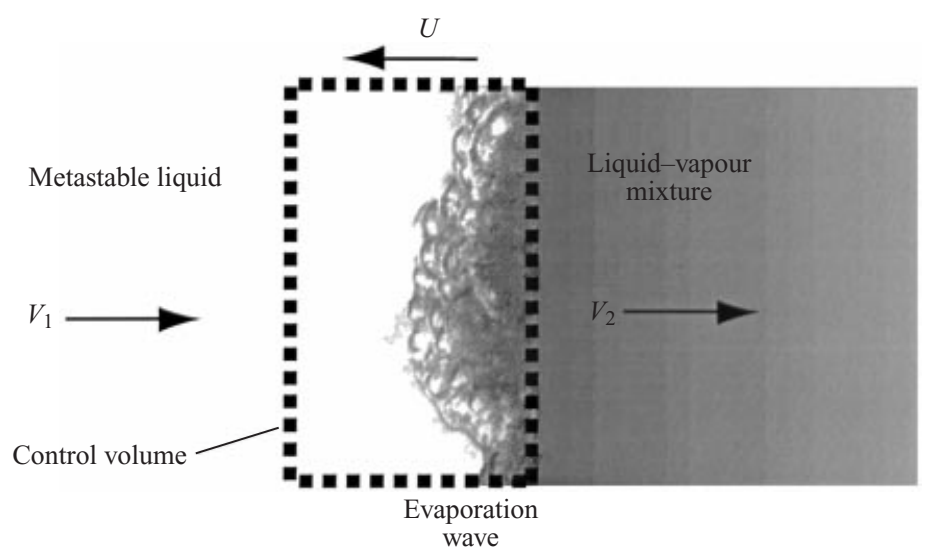

FIGURE 1. Control volume enclosing the evaporation wave. The evaporation wave is moving to the left with an average velocity $U$.

\section{Control-volume analysis}

The analysis is based on an integral formulation of the conservation relations for a control volume, $\mathrm{CV}$, enveloping a quasi-one-dimensional steady evaporation wave. Figure 1 illustrates the geometry of the model. The wave progresses steadily into the quiescent superheated liquid with velocity $U$. The $\mathrm{CV}$ is fixed in relation to the evaporation wave and moves with the wave as seen from a laboratory frame. The downstream flow is taken to be in thermal equilibrium and gravitational force effects are neglected. Transverse velocity components are considered small compared to the main axial velocity, and wall friction forces are neglected. In the experiments, the flow is observed to be slightly unsteady and spatially non-uniform. We will not consider these effects in this report; discussion of these issues can be found in Simões-Moreira (1994) and McCahan (1992).

In the wave frame, the superheated liquid enters the $\mathrm{CV}$ with velocity $U+V_{1}$ and a two-phase mixture leaves the $\mathrm{CV}$ with velocity $U+V_{2}$. Subscript 1 refers to superheated liquid upstream of the wave and subscript 2 the flow downstream of the wave. Define the relative velocities $W$ as

$$
W_{1}=U+V_{1},
$$

and

$$
W_{2}=U+V_{2} .
$$

In the current experiments, the liquid was stationary and the velocity $V_{1}$ was zero. Let square brackets, [ ], indicate a jump in the enclosed property, that is, $[f]=f_{2}-f_{1}$. Then the conservation equations for mass, momentum and energy can be written as

$$
\begin{gathered}
{[J]=0,} \\
{[P+J W]=0,}
\end{gathered}
$$

and

$$
\left[h+\frac{1}{2} W^{2}\right]=0,
$$

where $h$ is the specific enthalpy and $J$ is the superficial mass flux

$$
J=\frac{W_{1}}{v_{1}}=\frac{W_{2}}{v_{2}},
$$


where $v_{i}$ is the corresponding upstream or downstream average specific volume. Combining the balance equations, one can obtain the Rayleigh equation,

$$
J^{2}=-\frac{[P]}{[v]},
$$

and the Rankine-Hugoniot equation,

$$
[h]=\frac{v_{1}+v_{2}}{2}[P] .
$$

An equation of state must be supplied to estimate the downstream thermodynamic properties. For single-phase states, a conventional $P(v, T)$ equation and ideal gas heat capacity $c_{p}^{i g}(T)$ suffice. For two-phase states, some assumptions must be made about the relationship between the phases. The simplest notion is to assume that the phases are in mechanical and thermal equilibrium. Then the relevant extensive thermodynamic variables can be computed by mass averages of the properties of the individual phases. An additional variable, the quality or vapour mass fraction $x$, is introduced and an additional constraint, the saturation condition $P=P_{\sigma}(T)$, is added. The saturated vapour pressure is denoted by $P_{\sigma}(T)$. The issue of mechanical equilibrium, i.e. relative motion between liquid and vapour phases, in the downstream flow will be discussed in $\S 5$.

In either the single- or two-phase regions, there is one more variable than there are equations so that these equations do not uniquely determine the wave speed unless a downstream property can be specified. Evaporation wave speed at a given time will be a function of the initial and boundary conditions for that flow. Only in special cases can the wave speed be considered to be uniquely fixed without taking into account details of the flow field. In general, a family of solutions will be found, and these are parameterized by either the wave speed or a downstream property. In addition to (7) and (8), the entropy constraint, $s_{2} \geqslant s_{1}$, must also be satisfied.

Our formulation of the control-volume analysis of an evaporation wave is similar to that of a subsonic deflagration wave in a combusting gas. The energy stored in the superheated liquid plays the same role as the energy stored in the molecular bonds of the reactants. The solution to (7) and (8) lies on an evaporation adiabat or Hugoniot curve. A graphical analysis of these equations is shown in the $P, v$ diagram in figure 2 . $P_{1}$ is the upstream metastable pressure; from the initial state $\left(P_{1}, v_{1}\right)$ the Rayleigh line, $R$, extends downward. The slope of the Rayleigh line is given by (7) and represents the square of the superficial mass flux $J$. The curved line passing through points $A, B$, and $C$ is the evaporation adiabat which is the locus of downstream states that satisfies (8).

Possible downstream states are given by the intersection (points $A, B$ and $C$ ) of the Rayleigh line with the evaporation adiabat. For Rayleigh lines $R$ with slopes larger than $R^{\prime}$, two solutions, $A$ and $C$, represent possible downstream states. As the superficial mass flux $J$ increases, a limiting case is reached when the Rayleigh line is tangent to the evaporation adiabat and only one solution $B$ exists, known as the lower Chapman-Jouguet or CJ point. No solutions exist for flow rates larger than this value. An upper branch of the adiabat representing compression waves also exists (Shepherd, McCahan \& Cho 1990) and associated with it is a second (upper) CJ point. However, in general, these solutions do not appear relevant to the evaporation wave problem (Shepherd et al. 1990; McCahan \& Shepherd 1993), therefore the CJ point referred to subsequently is always the lower one.

The standard (Thompson 1972) thermodynamic analysis of the CJ point is applicable to this situation. At the point $B$, the mass flow rate is a maximum and the 


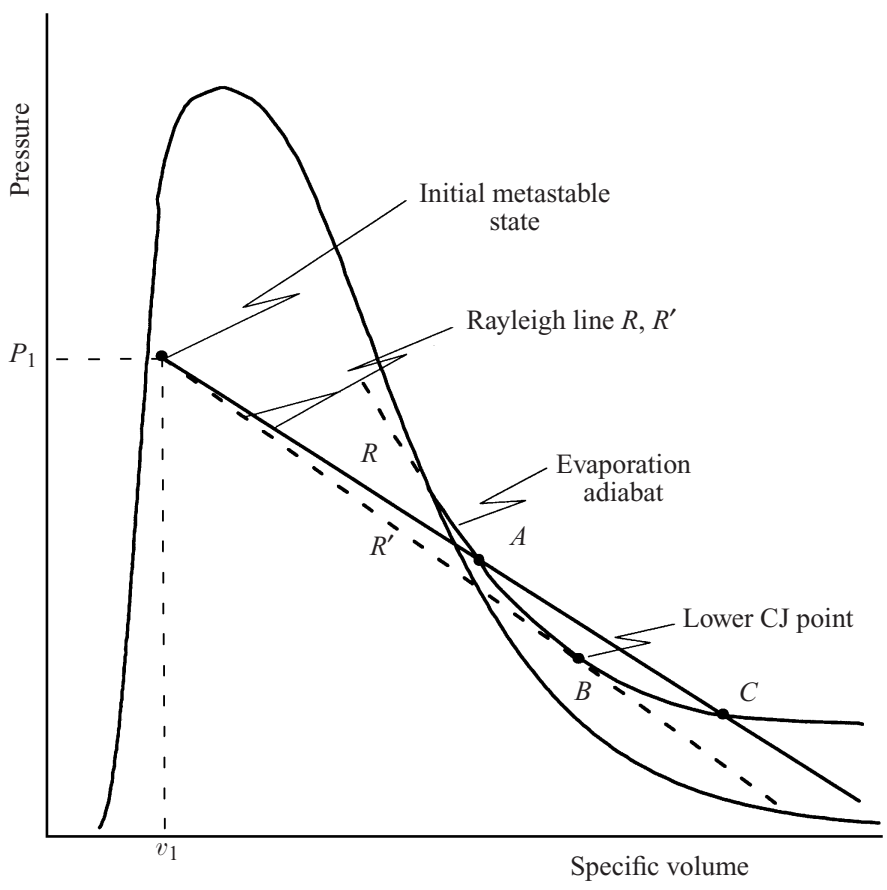

FIGURE 2. Graphical illustration of possible downstream solutions for an evaporation wave with a known upstream state.

flow is sonic, i.e. the flow velocity downstream (relative to the wave) is equal to the equilibrium sound speed. For each solution $A$ to the left of the CJ-point $B$, there is a corresponding point $C$ on the right-hand side of the CJ point. These points represent subsonic $(A)$ and supersonic $(C)$ downstream solutions, respectively. In the present experiments, only downstream states of the type $A$ or $B$ were obtained.

It can be shown that the CJ point is a local entropy maximum. For a fixed upstream state, the Rankine-Hugoniot relation (8) is differentiated and combined with the fundamental relation of thermodynamics,

$$
\mathrm{d} h_{2}=T_{2} \mathrm{~d} s_{2}+v_{2} \mathrm{~d} P_{2},
$$

to obtain

$$
\mathrm{d} s_{2}=\frac{[v]^{2}}{2 T_{2}} \mathrm{~d} J^{2} .
$$

Consequently, the entropy variation has the same sign and trend as the variation of the square of the superficial mass flux $J$. At the CJ point, the graphical analysis of figure 2 demonstrates that $J$ is a maximum. Therefore, an entropy maximum is reached at the lower $\mathrm{CJ}$ point for a fixed upstream state. This implies that the isentrope, Hugoniot curve and Rayleigh line are all tangent at the CJ point, which leads us to the conclusion that the downstream flow travels at the local speed of sound relative to the wave.

An important simplification is obtained when the vapour phase of the downstream flow behaves as an ideal gas, with $v_{2} \approx v_{V} \gg v_{L}$, which is generally true for states 
sufficiently far away from the critical point. Then, the Rayleigh equation yields

$$
J^{2}=\left(\frac{W_{2}}{v_{2}}\right)^{2} \approx-\frac{[P]}{v_{2}} .
$$

Further simplification is possible at the CJ point where $W_{2}=C_{2}=\left(\gamma R T_{2}\right)^{1 / 2}$, the local speed of sound. Combining these relations and substituting into (11), we obtain

$$
P_{2} \approx \frac{P_{1}}{1+\gamma} .
$$

The specific heats ratio $\gamma$ for ideal gases is always in the range 1 to $5 / 3$, which means that $P_{2}$ is $37-50 \%$ of the metastable pressure $P_{1}$. We found that this is a useful rule of thumb for estimating the downstream pressure in our experiments.

\section{Experimental setup and procedure}

A schematic of the test facility is shown in figure 3 . The main components were a heated glass test cell and a low-pressure chamber. The test cell consisted of a round Pyrex glass tube, whose dimensions were $340 \mathrm{~mm}$ long by $15 \mathrm{~mm}$ diameter. Glass was chosen because its surface was smooth enough to suppress undesirable heterogeneous nucleation and made photographic documentation possible. Circulation of hot air in a square glass jacket partially enclosing the cell was used to heat the system to the desired temperature. To ensure the uniformity of the initial temperature, a thermocouple was traversed within the test cell, and the heat supply was adjusted as necessary.

A diaphragm, made of Kapton in most experiments and aluminium in a few cases, closed the top part of the cell and served to isolate the test liquid from a low-pressure chamber. Each experiment involved discharging about $50 \mathrm{~cm}^{3}$ of liquid dodecane from the test cell into the low-pressure chamber $\left(0.227 \mathrm{~m}^{3}\right)$. We began the experiment by piercing the diaphragm, which rapidly depressurized the liquid (see figure 6) and initiated evaporation. The diaphragm was pierced by using an arrow with four knife blades driven by a compressed-air piston actuated by a solenoid valve. The blades were at a shallow angle to the horizontal $\left(5^{\circ}\right)$ so that the total piercing time of the diaphragm was a few milliseconds.

Substantial efforts were made to suppress nucleation at the bottom of the cell. The pressure and temperature transducers located in the bottom flange were efficient nucleation sites as was the gasket between the flange and the glass cell. The ultimate solution to premature nucleation at the cell bottom consisted of cooling the bottom portion of the test cell and allowing it to protrude below the heated section. This introduced a temperature gradient into the last $2 \mathrm{~cm}$ of test liquid and data from evaporation in this portion of the cell were not used.

Pressure transducers were located at the bottom of the cell and near the cell exit. The bottom transducer was mounted flush with the flange. The exit transducer was mounted remotely in a small aluminium block and water cooled to prevent thermal damage. The exit pressure signal was transmitted through a small steel tube $(3.18 \mathrm{~mm}$ diameter and about $100 \mathrm{~mm}$ long) from the test cell to the pressure transducer. Exit temperatures were obtained using a T-type thermocouple with a bead diameter of $0.6 \mathrm{~mm}$, which had an estimated response time of 50-100 ms. Signals were amplified and then recorded using a digital data acquisition system.

We obtained simultaneous still photographs using two cameras and a short-duration $(0.5 \mu \mathrm{s})$ light source. One camera imaged a front view of the test cell and the other 


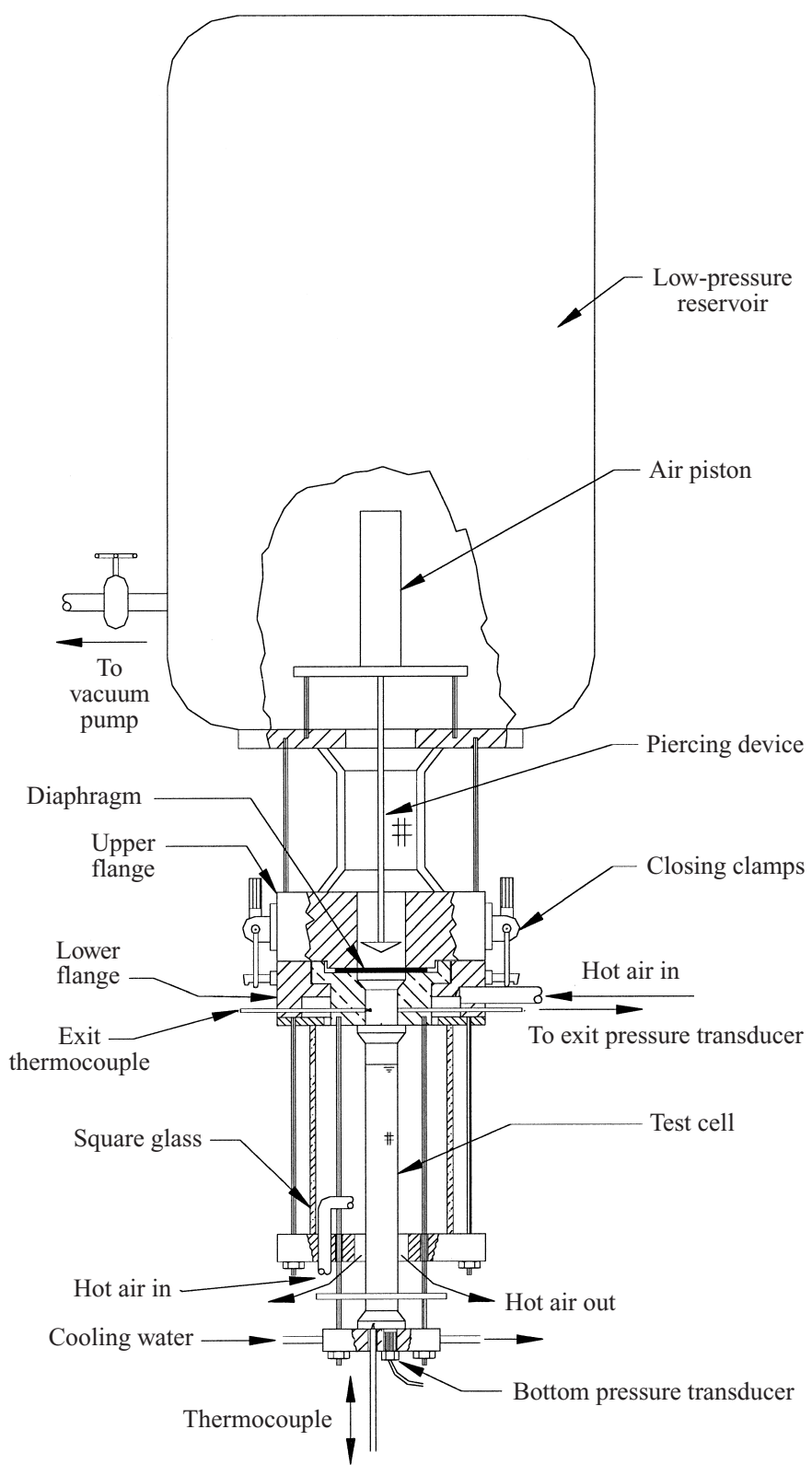

FIGURE 3. Diagram of the test facility.

imaged the evaporation wave at $30^{\circ}$ to the wave plane. The light triggering signal came from a photosensor that was illuminated by a laser beam passing through the test cell. As soon as the evaporation wave passed by, it blocked off the beam causing the photosensor circuit to generate an electrical pulse, which then triggered the light source. Motion pictures with a framing rate of 3000 frames per second were also obtained. These films revealed details of the development of the evaporation wave and enabled accurate measurements of the wave speed. Video recording was used in many experiments to get a quick indication of the results. Diffuse lighting from behind the cell was used in all cases to minimize refractive effects. 


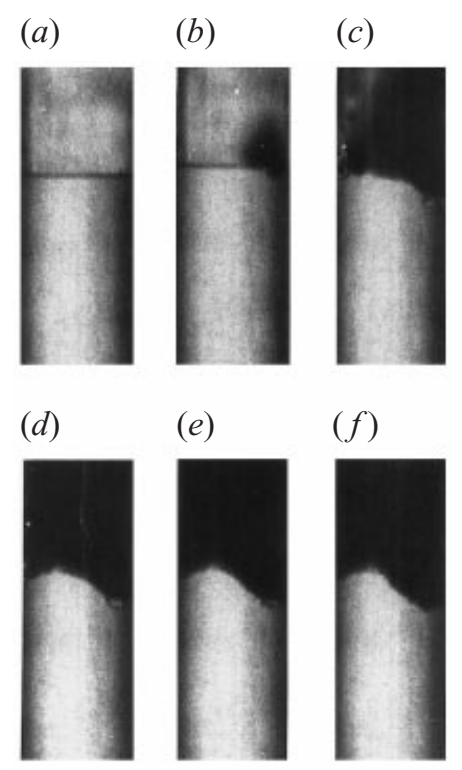

FiguRE 4. Initiation of an evaporation wave as recorded by motion pictures $\left(T_{0}=270^{\circ} \mathrm{C}\right.$, $P_{R E S}=1$ mbar, $U=83.7 \mathrm{~m} \mathrm{~s}^{-1}$, test dd-f-71). Successive frames are approximately $0.33 \mathrm{~ms}$ apart. The evaporation wave is moving downward and the diaphragm is located out of the field of view, approximately $5 \mathrm{~cm}$ above the free surface of the liquid.

We started a typical test by degassing the dodecane at room temperature. Then, we filled the test cell, installed the diaphragm, and a second low-pressure degassing process would take place while the system was being heated. After boiling for some time, the glass cell was pressurized with a cover gas $\left(\mathrm{N}_{2}\right)$. The pressure was controlled inside the test cell so that the liquid was slightly above the saturation pressure. The low-pressure reservoir was evacuated and then brought up to the desired pressure with $\mathrm{N}_{2}$. Once the test temperature was reached, the photographic system (motion or still pictures) and the data acquisition were set up. The triggering signal for the data acquisition was either from the motion picture camera or from the diaphragm piercing system. The total data acquisition time was in the range of 200-500 ms, depending on the individual experiment. More details on the experimental setup can be found in Simões-Moreira (1994).

\section{Experimental results}

A sequence of motion pictures is shown in figure 4 . The initial test temperature was $270^{\circ} \mathrm{C}$, and the initial reservoir pressure was about $1 \mathrm{mbar}$. The first picture $(a)$ shows in the upper left corner the test cell immediately before the evaporation started and emphasis is given to the initial liquid-vapour surface. The next picture $(b)$ registered the moment of nucleation at the initial free surface. It seems that for this particular run, the initiation of the phenomenon was at the liquid-vapour free surface and the contact line with the test cell. The following photographs show the evaporation wave progressing downwards into the undisturbed regions of the metastable liquid. These photographs are individual frames in a sequence from a high-speed film.

The sequence of photographs shows that the evaporation front was a very irregular interface, which displayed different shapes as it progressed. If one assigned a plane 
to the average evaporation front, a normal vector to this plane fluctuated about the axial direction. Nevertheless, it was always possible to observe a mean evaporation wave region with a well-defined velocity of propagation characterized by a standard deviation of $1 \%$ to $2 \%$. The velocity of propagation was obtained from motion pictures using the method of least squares for fitting the position vs. time data. The time reference for the motion pictures was obtained from the $10 \mathrm{~ms}$ timing-light marks on the film.

The downstream region can be characterized by three distinct portions visible in the motion pictures. Streaks of low-speed liquid could be seen flowing along the test cell walls. The core region was formed by the flow of high-speed vapour phase and fine droplets entrained in the mean stream. In the terminology of two-phase flow, the closest classification would be annular flow with liquid entrainment. The farther downstream the two-phase flow was from the evaporation front, the less light was scattered, which was also confirmed by some still pictures. This can be interpreted as the presence of a considerable dense mist of fine droplets right behind the evaporation front and its dissipation downstream either by evaporation or by attachment to the liquid structures flowing at the wall.

The still pictures of figure 5 show front views of evaporation waves at six different test conditions spanning the range of initial temperatures covered in our experiments. The wave is moving from top to bottom. The evaporation front is a highly-disturbed region formed by many interconnected hemispherical surfaces that resemble portions of bubbles. The still pictures alone cannot precisely resolve the upper portion of these structures sufficiently to determine whether they are open or closed. Motion pictures and videos $\dagger$ give a distinct impression of a somewhat jerky microscopic motion at low superheats that becomes smoother (and faster) with increasing superheat.

Hill obtained the first high-resolution photographs (Hill \& Sturtevant 1990; Hill 1991) of the wave initiation and startup process in refrigerants R12 and R114. Our photographs are strikingly similar to his, indicating that the structure of the front is not dependent on substance. Hill found, as we did, that the front appeared to be composed of bubble-like structures and bursting of these structures gave rise to a 'streak' of droplets in the two-phase flow region downstream of the wave. This is particularly evident in the motion pictures and videos. A certain amount of liquid is also obviously attached to the test vessel surfaces and moving at a lower velocity than the free stream. These observations are incorporated into the model for velocity slip that is developed in $\S 5$.

Analysis of the still pictures revealed that the average size of hemispherical structures in the front decreased as the test temperature increased. At the same time, the two-phase flow region appeared to become more homogeneous and less 'streaky'. In some photographs, there are artifacts, longitudinal streaks, due to the refraction and lensing effect of the cylindrical test cell. It is difficult to precisely quantify the distribution of hemispherical structure sizes. Inspection of the photographs indicated that the structures had a maximum size of up to $5 \mathrm{~mm}$ (diameter) at low $\left(200^{\circ} \mathrm{C}\right)$ superheats and less than $1 \mathrm{~mm}$ at the highest superheat $\left(290^{\circ} \mathrm{C}\right)$ studied. A spectrum of sizes was visible, down to the smallest scales, less than $100 \mu \mathrm{m}$, that could be resolved by the photography. These structures appear to be very similar in appearance to those observed by Hill (1991) and comparable in size, 0.1 to $1 \mathrm{~mm}$. The structure lifetime

$\dagger$ A video tape of the motion pictures for selected experiments is available for the cost of handling. Contact the authors at jeshep@galcit.caltech.edu. 
(a)

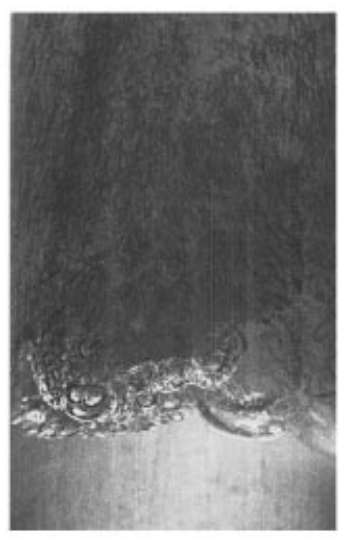

(d)

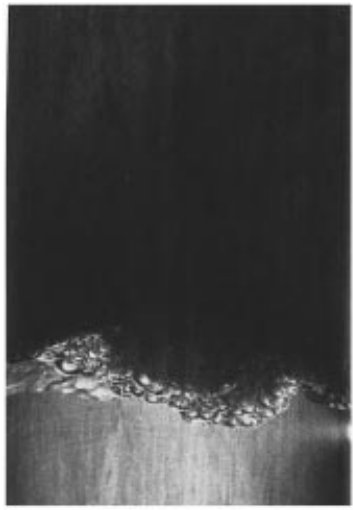

(b)

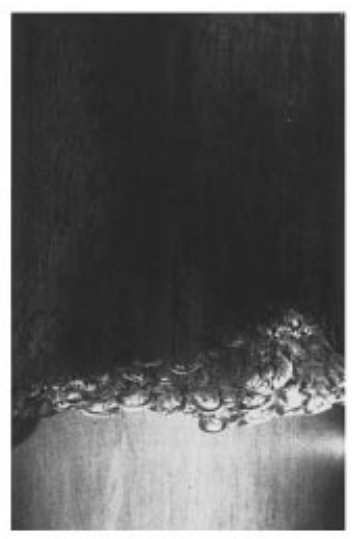

(e)

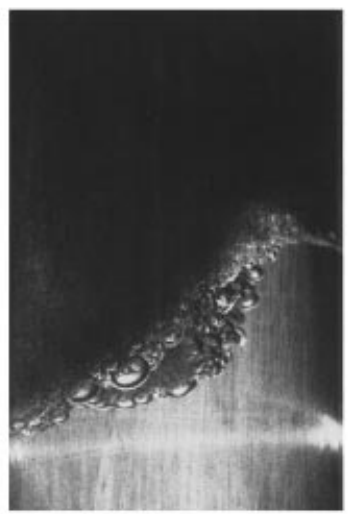

(c)

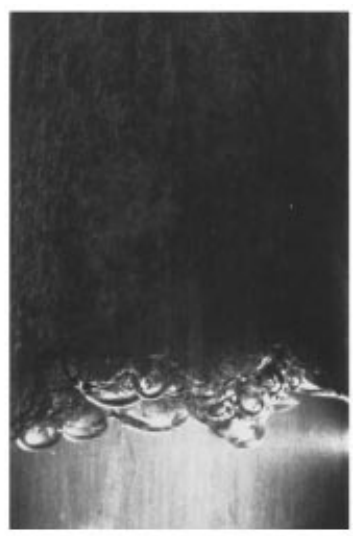

(f)

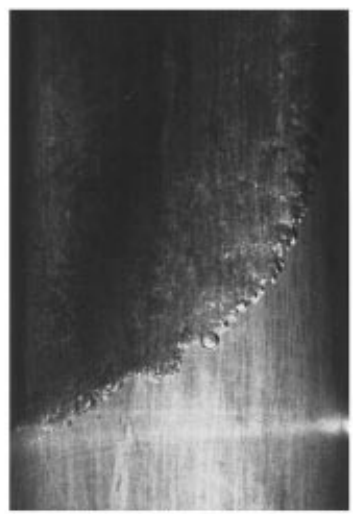

FIGURE 5. Selected still pictures, front views. (a) $T_{0}=180^{\circ} \mathrm{C}, P_{R E S}=1 \mathrm{mbar}$, test dd-p-109; (b) $T_{0}=200^{\circ} \mathrm{C}, P_{R E S}=1$ mbar, test dd-p-110; (c) $T_{0}=230^{\circ} \mathrm{C}, P_{R E S}=1$ mbar, test dd-p-112; (d) $T_{0}=250^{\circ} \mathrm{C}, P_{R E S}=1$ mbar, test dd-p-113; (e) $T_{0}=270^{\circ} \mathrm{C}, P_{R E S}=1$ mbar, test dd-p-114; (f) $T_{0}=290^{\circ} \mathrm{C}, P_{R E S}=1$ mbar, test dd-p- 115 .

measured in the present experiments was in the order of $1 \mathrm{~ms}$, comparable to that observed by Hill.

Earlier studies (Shepherd \& Sturtevant 1982; Frost \& Sturtevant 1986; Frost 1988) on vapourization waves in superheated droplets also demonstrated the existence of highly-disturbed evaporating surfaces and two-phase flows in other superheated hydrocarbons such as butane and ether. Those observations were interpreted in terms of the instability of a strongly evaporating surface. The reasoning applied in those cases is equally valid in the present flow but our observations are not sufficiently detailed to determine how instabilities such as the Landau mechanism play a role. The structure and dynamics of unstable evaporation waves still remains to be elucidated. Additional discussion on this point is provided in Chapter 6 of Simões-Moreira (1994).

Pressure and temperature traces obtained in test dd-f-71 are shown in figure 6, corresponding to the motion picture frames of figure 4. Sharp drops in pressure and exit temperature occurred when the diaphragm burst. Typically, the exit pressure 


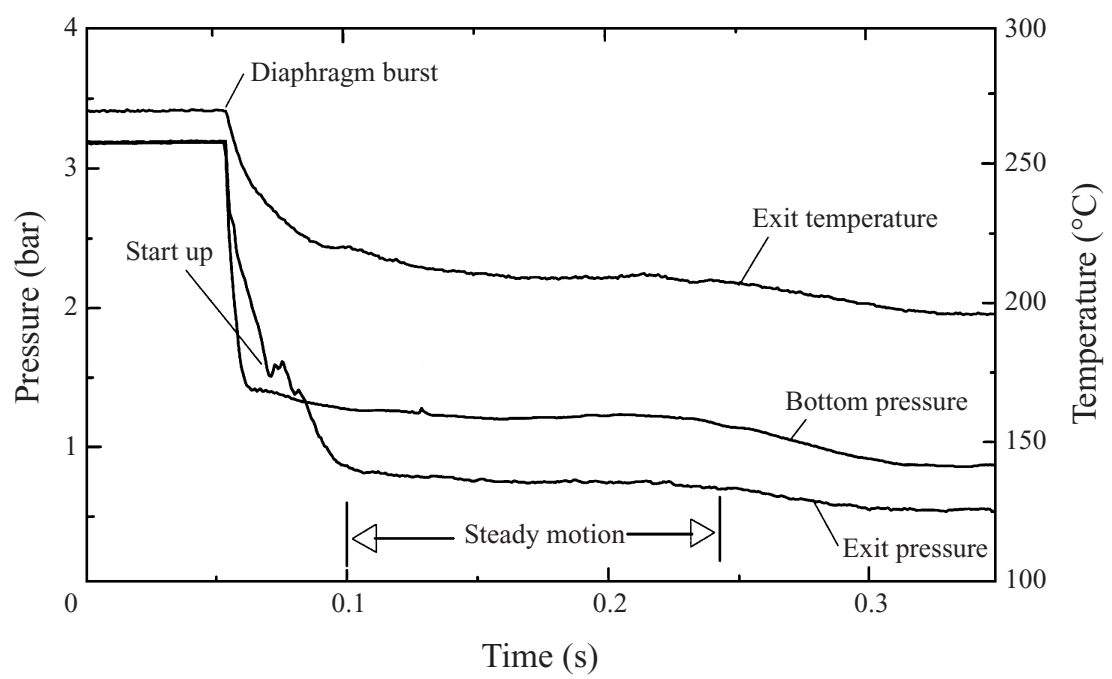

FIGURE 6. Example of pressure and temperature signals obtained in the experiments $\left(T_{0}=270^{\circ} \mathrm{C}, P_{R E S}=1 \mathrm{mbar}, U=83.7 \mathrm{~m} \mathrm{~s}^{-1}\right.$, test dd-f-71).

displayed a slight recovery and recompression immediately after the depressurization (labelled 'start up' in figure 6), which was associated with the startup of the evaporation wave. The signals were approximately constant during the time period (labelled 'steady motion' in figure 6) representing the steady propagation of the evaporation wave. The decreasing signals at late times (after $25 \mathrm{~ms}$ ) were due to the slower evaporation of cooler liquid at the bottom of the cell.

In some experiments, a delay of $2-3 \mathrm{~ms}$ was observed between diaphragm rupture and the onset of the evaporation wave. During this time, acoustic waves reverberate within the liquid and a slight cooling (we estimate about $0.01^{\circ} \mathrm{C}$ ) took place. Chaves et al. (1987) suggested that the onset of evaporation occurs upon the arrival of the first rarefaction wave reflected from the bottom of the test cell. Hill (1991) observed that the time delay between the first expansion wave and wave onset was enough to accommodate several acoustic transits in his experiments with refrigerants. Our results are consistent with Hill's findings and we refer the reader to his excellent photographs and discussion of the startup process, in which an evaporation front spreads across the initially quiescent surface and develops into an unstable evaporation wave.

The average pressure jump across the evaporation wave was estimated as the pressure difference between the top and bottom of the cell. Corrections were estimated (Simões-Moreira 1994) for the gravitational head and the pressure drop in the twophase region and found to be of the same order as the experimental uncertainties.

Two sets of experiments were performed. The main goal of the first set, the 'choked series', was to search for the complete evaporation wave. The results of that search are discussed in $\S 6$. Test conditions and measured wave speeds in the choked series are summarized in table 1: $T_{\text {test }}$ is the initial test temperature; $P_{\sigma}$ is the saturation pressure; $P_{B}$ is the pressure at the bottom of the test cell; $P_{E}$ is the exit pressure; and $U$ is the average velocity of propagation obtained from analyses of the motion pictures. All experiments from this series were carried out with the reservoir evacuated to a pressure of less than 1 mbar. Thermodynamic properties such as liquid and vapour densities were estimated from the Lee \& Kesler (1975) equation of state. A short list of important dodecane properties is given in table 2 . 


\begin{tabular}{cccccc}
\hline$T_{\text {test }}$ & $\begin{array}{c}P_{\sigma} \\
\left({ }^{\circ} \mathrm{C}\right)\end{array}$ & $\begin{array}{c}P_{B} \\
(\text { bar })\end{array}$ & $\begin{array}{c}P_{E} \\
(\text { bar })\end{array}$ & $\begin{array}{c}U \\
(\text { bar })\end{array}$ & $\left(\mathrm{cm} \mathrm{s}^{-1}\right)$ \\
180 & 0.39 & 0.24 & 0.18 & 25.3 \\
200 & 0.68 & 0.33 & 0.22 & 30.9 \\
216 & 1.00 & 0.44 & 0.28 & 39.0 \\
230 & 1.39 & 0.59 & 0.37 & 47.2 \\
250 & 2.12 & 0.83 & 0.52 & 64.8 \\
270 & 3.12 & 1.19 & 0.73 & 83.7 \\
290 & 4.45 & 1.91 & 1.16 & 138.1 \\
300 & 5.26 & 2.12 & 1.32 & 157.8
\end{tabular}

TABLE 1. Experimental results: choked flow series of tests.

\begin{tabular}{|c|c|c|c|c|c|}
\hline & $\begin{array}{l}\text { Mo } \\
\text { Crit } \\
\text { Crit } \\
\text { Crit } \\
\text { Ace } \\
\text { Nor }\end{array}$ & $\begin{array}{l}\text { mass } \\
1 \text { pressure } \\
1 \text { tempera } \\
1 \text { volume } \\
\text { ic factor } \\
1 \text { boiling }\end{array}$ & & $\begin{array}{c}170.34 \\
18.2 \\
385.05 \\
713 \\
0.575 \\
216.3\end{array}$ & $\begin{array}{l}\mathrm{g} \mathrm{mol}^{-1} \\
\mathrm{bar} \\
{ }^{\circ} \mathrm{C} \\
\mathrm{cm}^{3} \mathrm{~mol}^{-1} \\
{ }^{\circ} \mathrm{C}\end{array}$ \\
\hline & \multicolumn{5}{|c|}{ TABle 2. Dodecane properties (Reid, Prausnitz \& Poling 1987). } \\
\hline $\begin{array}{c}P_{R} \\
\text { (bar) }\end{array}$ & $\begin{array}{c}P_{E} \\
\text { (bar) }\end{array}$ & $\begin{array}{c}P_{B} \\
\text { (bar) }\end{array}$ & $\begin{array}{c}U \\
\left(\mathrm{~cm} \mathrm{~s}^{-1}\right)\end{array}$ & & \\
\hline $1.3-0.8$ & $1.3-0.8$ & $1.3-0.8$ & - & train & bbles or unstable wave \\
\hline 0.7 & 0.700 & 0.702 & 8.1 & evap & wave and slug flow bubble \\
\hline 0.6 & 0.62 & 0.66 & 29.0 & thres & or evaporation wave \\
\hline 0.5 & 0.54 & 0.62 & 39.4 & evap & have \\
\hline 0.4 & 0.41 & 0.61 & 45.3 & evap & wave \\
\hline 0.3 & 0.37 & 0.60 & 47.2 & evap & nave \\
\hline 0.2 & 0.46 & 0.61 & 45.7 & evap & a wave \\
\hline 0.1 & 0.44 & 0.61 & 46.5 & evap & n wave \\
\hline 0.0 & 0.37 & 0.59 & 47.2 & evap & n wave \\
\hline
\end{tabular}

The second set of experiments, the 'isothermal series', was designed to investigate the subsonic branch of the Rankine-Hugoniot curve. To achieve this goal, the liquid was exposed to decreasing values of the reservoir pressure at a fixed liquid temperature $\left(230^{\circ} \mathrm{C}\right)$. Wave velocities were computed in these cases by analysing video images. Results are given in table 3 . Note that the saturation pressure of dodecane at $230^{\circ} \mathrm{C}$ is 1.387 bar. Our general observations are as follows.

$1.2 \leqslant P_{R} \leqslant 1.3$ bar. At low superheats, i.e. reservoir pressures close to the saturation pressure (1.387 bar), a wave did not start. Nucleation started at the interface of the free surface and the glass tube and then the nucleation process moved randomly down the tube wall.

$0.7 \leqslant P_{R} \leqslant 1.1$ bar. As the reservoir pressure was decreased, an evaporation wave appeared to start, but nucleation usually occurred somewhere upstream in the liquid. Usually, a single slug-flow-type bubble grew until it filled the tube and expelled the liquid above it. At $P_{R}=0.7$ bar, it was possible to observe a stable evaporation wave initially but nucleation disrupted the process eventually. 
$P_{R} \leqslant 0.6$ bar. Lower reservoir pressure resulted in the consistent formation of evaporation waves. Waves started promptly and propagated with a characteristic velocity. No nucleation upstream was observed.

$P_{R} \leqslant 0.3$ bar. Beyond a certain point, the exit pressure would be independent of the reservoir pressure. The evaporation wave properties were insensitive to further decreasesy in the reservoir pressure. We believe that this was due to the two-phase flow reaching a choking condition.

These results are in agreement with the earlier experiments in water (Grolmes \& Fauske 1974), perfluoro-heptane (PP1) (Thompson et al. 1987), and refrigerants 12 and 114 (Hill \& Sturtevant 1990; Hill 1991). There was a noticeable threshold, at which an evaporation wave could be formed and sustained. There were also definite limits of minimum and maximum superheats for which we reliably observed evaporation waves. Outside these limits, nucleation upstream of the wave would disrupt our observations. At low superheats, the evaporation wave was slow and there was a long dwell time before the onset of the wave. This required metastable fluid to be in the test cell for a long period of time, and heterogeneous nucleation would occur. At moderate superheats, the wave would start promptly and move quickly enough that heterogeneous nucleation upstream of the wave would not occur. At high superheats, the nucleation rate became so high that despite high evaporation wave speeds, heterogeneous nucleation occurred upstream of the wave.

\section{Modelling the velocity slip}

The jump conditions $(\S 2)$ can be used to solve for the downstream state given the upstream conditions and one other piece of information, such as the wave speed or downstream pressure. An important case that admits such a solution is the situation of an equilibrium homogeneous two-phase flow state downstream. In this case, the condition of mechanical equilibrium implies that the relative average downstream velo- city is common between phases, $W_{2}=W_{L 2}=W_{V 2}$. The condition of thermodynamic equilibrium implies that the average downstream thermodynamic (specific) properties $\bar{f}$ are obtained using the mixture rule $\bar{f}=x f_{V}+(1-x) f_{L}$, where $x$ is the vapour quality, $f_{V}$ is the saturated vapour thermodynamic property, and $f_{L}$ is the saturated liquid thermodynamic property. The jump equations (3)-(5) can be solved to obtain the vapour quality explicitly

$$
x=\frac{h_{1}-h_{L 2}+\left(v_{L 2}+v_{1}\right)[P] / 2}{h_{L V 2}-v_{L V 2}[P] / 2},
$$

where $v_{L V}=v_{V}-v_{L}$ and $h_{L V}=h_{V}-h_{L}$.

Equation (13) allows the direct solution of the jump conditions in the case of a homogeneous downstream state. This was first pointed out by Thompson \& Sullivan (1975) in the context of liquefaction shock waves. There are no a priori limitations on the thermodynamic properties that would prevent the quality from being unity, i.e. a single-phase (vapour) downstream state. The implications of this are explored in more detail in the subsequent section. If the downstream state is a single phase, then a numerical solution of the jump conditions will generally be required.

The homogeneous equilibrium model is appealing for its simplicity but our motion pictures suggest that the downstream flow is not in mechanical equilibrium. As discussed in $\S 4$, three regions were observed downstream of the flow: (i) a slowly moving liquid phase attached to the wall, (ii) a faster moving vapour phase in the core region, and (iii) entrained liquid droplets in the core region, which were assumed 
to flow at the speed of the vapour phase. In terms of traditional two-phase flow terminology, the flow can be classified as an annular flow with liquid entrainment.

A more realistic model should allow for the velocity of the liquid film (at the wall) and the vapour phase to be different. This can be accomplished by straightforward extensions based on classical two-phase flow modelling (Wallis 1969; Hewitt \& HallTaylor 1970). Property and velocity values are treated as uniform within a phase domain but the phases have different velocities. Define a slip parameter

$$
D_{W}=\frac{W_{L 2}}{W_{V 2}},
$$

which is related to the thermodynamic state through an empirical correlation such as Fauske's (1962)

$$
D_{A}=\left(\frac{v_{L 2}}{v_{V 2}}\right)^{1 / 2} .
$$

The parameter $D$ is reference-frame dependent, the subscript $W$ is used whenever the parameter refers to the wave frame and the subscript $A$ is used when the value is referred to the absolute or laboratory frame. In terms of a moving reference frame, the slip ratio $D_{W}$ can be written as

$$
\frac{D_{W} W_{V 2}-U}{W_{V 2}-U}=\left(\frac{v_{L 2}}{v_{V 2}}\right)^{1 / 2} .
$$

A sensitivity analysis was carried out assuming different values for the ratio between specific volumes. Varying the slip ratio by factor of $10^{3}$ results in only a $20 \%$ variation in the wave speed. Fauske's expression maximizes the superficial mass flux and therefore the evaporation wave speed. Some researchers prefer the cube root expression, which falls slightly lower than the square root expression. See figure 7.12 of Simões-Moreira (1994) for further details.

The mass flow rate of liquid along the wall must be distinguished from the liquid droplets in the main two-phase flow. In the present study, the film thickness was not measured. Suggestions for future work include using either light extinction or impedance techniques to quantify the liquid film. Two additional parameters are introduced into the model in order to account for the mass of liquid within the film. The void fraction $\alpha$ is defined as the time-average of the fraction of the cross-sectional area occupied by the vapour phase. The parameter $\beta$ specifies the time-average fraction of cross-sectional area occupied by the liquid film attached to the wall. Parameters $\alpha$ and $\beta$ are invariant with respect to the reference frame. In terms of these parameters, the fraction of liquid droplet mass flow relative to the total liquid mass flow is

$$
E_{W}=\left(1+\frac{\beta D_{W}}{1-\alpha-\beta}\right)^{-1} .
$$

Clearly, this will also be frame dependent.

Using these definitions, the conservation equations can be used to derive modified jump relations:

$$
\begin{gathered}
J=\frac{W_{1}}{v_{1}}=W_{V 2}\left\{\frac{\alpha}{v_{V 2}}+\frac{1-\alpha-\beta}{v_{L 2}}+\frac{\beta D_{W}}{v_{L 2}}\right\}, \\
P_{1}+\frac{W_{1}^{2}}{v_{1}}=P_{2}+W_{V 2}^{2}\left\{\frac{\alpha}{v_{V 2}}+\frac{1-\alpha-\beta}{v_{L 2}}+\frac{\beta D_{W}^{2}}{v_{L 2}}\right\},
\end{gathered}
$$




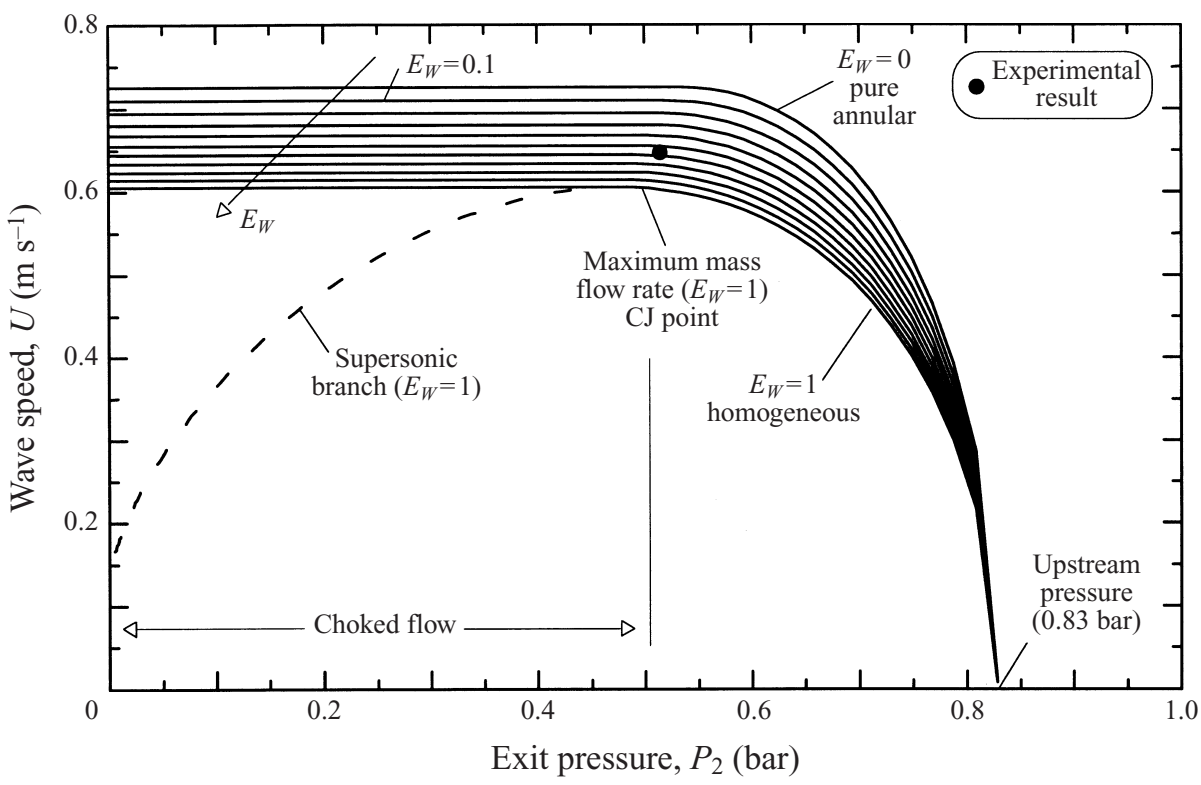

FiguRE 7. Numerical solution of the wave speed as function of the downstream pressure.

The fraction of liquid droplets $E_{W}$ is varied parametrically. The initial temperature is $T_{0}=250^{\circ} \mathrm{C}$.

and

$$
\begin{gathered}
\frac{W_{1}}{v_{1}}\left(h_{1}+\frac{W_{1}^{2}}{2}\right)=\frac{\alpha W_{V 2}}{v_{V 2}}\left(h_{V 2}+\frac{W_{V 2}^{2}}{2}\right)+\frac{\beta D_{W} W_{V 2}}{v_{L 2}}\left(h_{L 2}+\frac{\left(D_{W} W_{V 2}\right)^{2}}{2}\right) \\
+\frac{(1-\alpha-\beta) W_{V 2}}{v_{L 2}}\left(h_{L 2}+\frac{W_{V 2}^{2}}{2}\right) .
\end{gathered}
$$

Equations (18)-(20) and the slip correlation (16) were solved numerically (SimõesMoreira 1994) for a given upstream condition. The thermodynamic properties of dodecane were computed (Simões-Moreira 1994) using the Lee \& Kesler (1975) equation of state. A family of solutions is shown in figure 7 as a function of the entrainment parameter $E_{W}$ and the downstream pressure $P_{2}$. The homogeneous twophase flow model is the case $E_{W}=1$ and the annular two-phase flow without liquid entrainment is the case $E_{W}=0$. It can be seen in this and subsequent figures that the two limiting models envelop all solutions for different values of the liquid entrained parameter, $E_{W}$. In these solutions, the flow has been represented as choked (constant mass flux) when the pressure $P_{2}$ is less than the CJ pressure. One case of supersonic flow (dashed line) is shown to illustrate this type of solution. One data point is shown on this plot from the choked test series.

Figure 8 shows the graphical construction of the CJ solution for the two extremes $E_{W}=1$ and 0 . The tangent intersection of the Rayleigh line and the evaporation adiabat or Hugoniot is shown for both cases.

Comparisons of the model and experiment pressure and evaporation wave speed at the CJ condition (table 1) are shown in figures 9 and 10. The lower limit corresponds to numerical results for $E_{W}=1$ and the upper limit corresponds to $E_{W}=0$. Comparisons of computed and measured wave speeds (table 3) for the isothermal test series are shown in figure 11. For each case in table 3, the measured downstream 


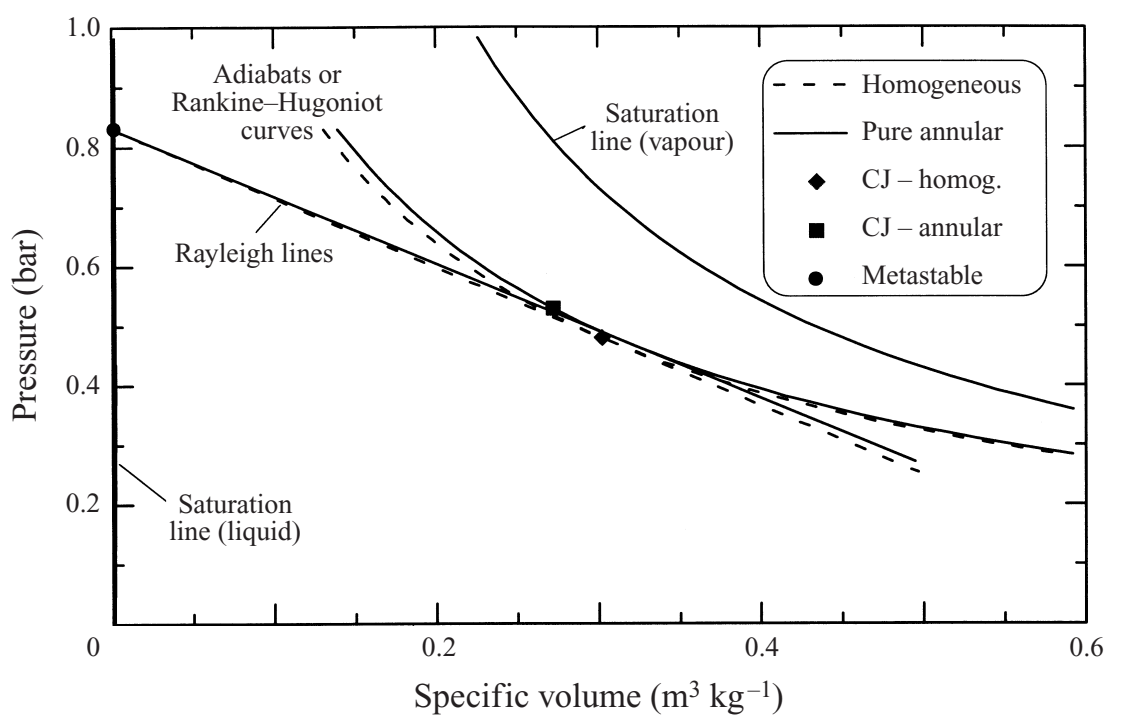

FIGURE 8. Rankine-Hugoniot curves or adiabats and Rayleigh lines for the CJ cases. Numerical solution for $T_{0}=250^{\circ} \mathrm{C}$.

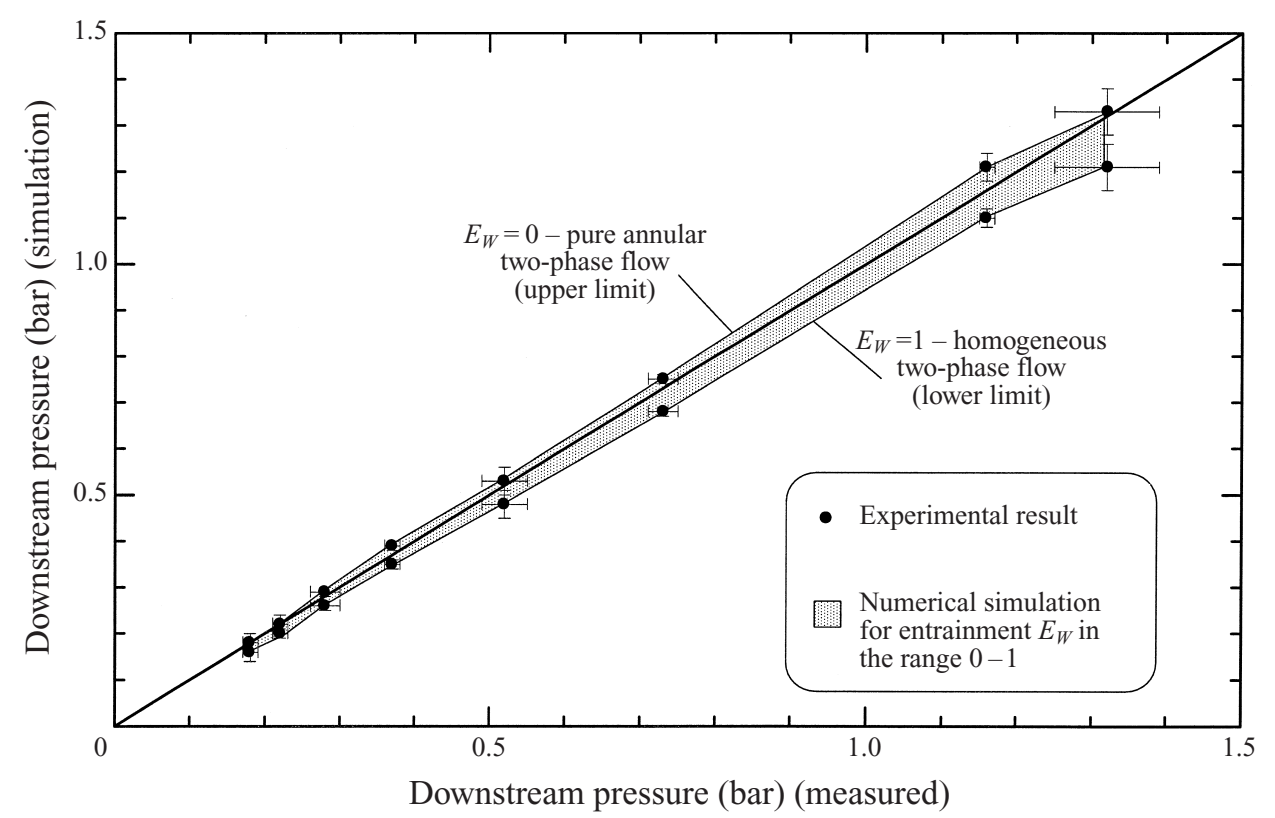

FIGURE 9. Comparisons of the numerical solution of the CJ pressure with the measured values for the choked series of tests (see table 1).

pressure was used as input to the computation to determine the wave speed for the subsonic family of solutions.

Figures 9 and 10 show that the annular flow model without liquid entrainment tends to overestimate both the downstream pressure and wave speed at the CJ point, while the homogeneous model tends to underestimate those quantities. On the other 


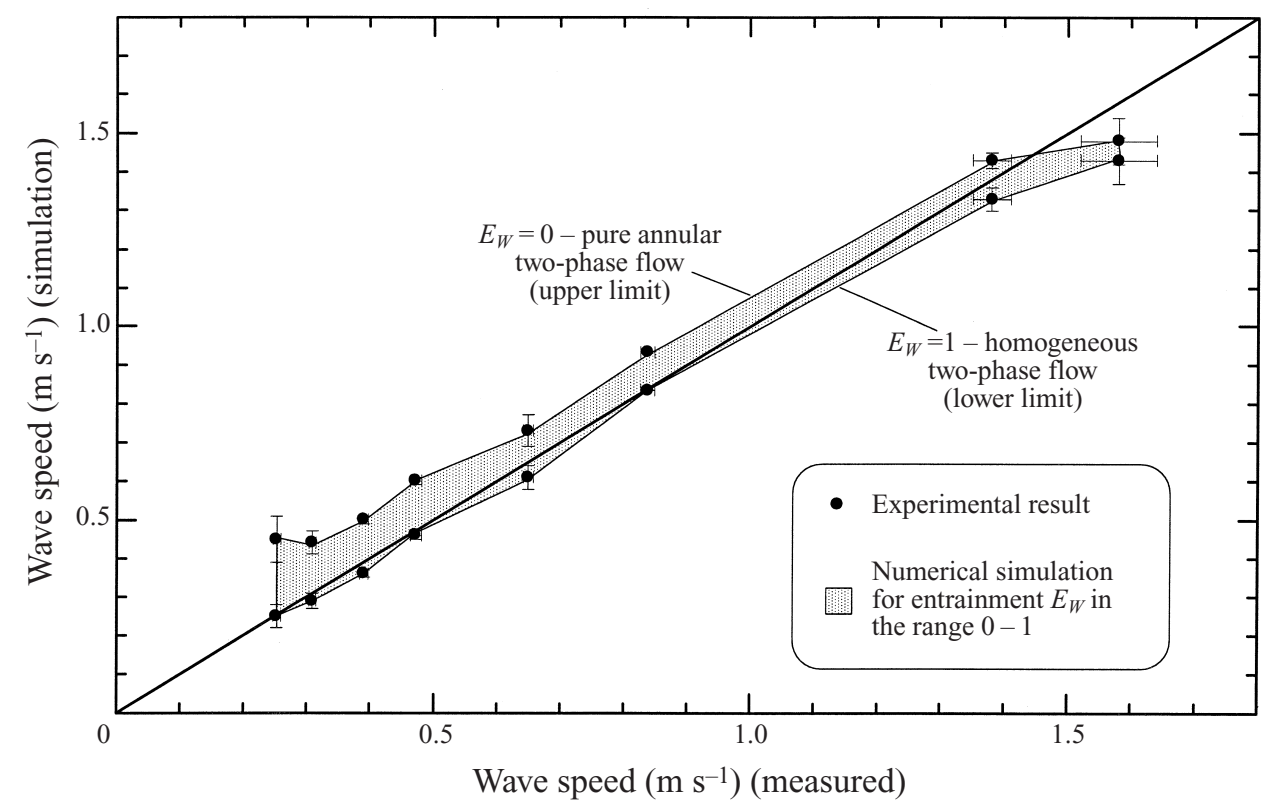

FIGURE 10. Comparisons of the numerical solution of the CJ wave speed with the measured values for the choked series of tests (see table 1).

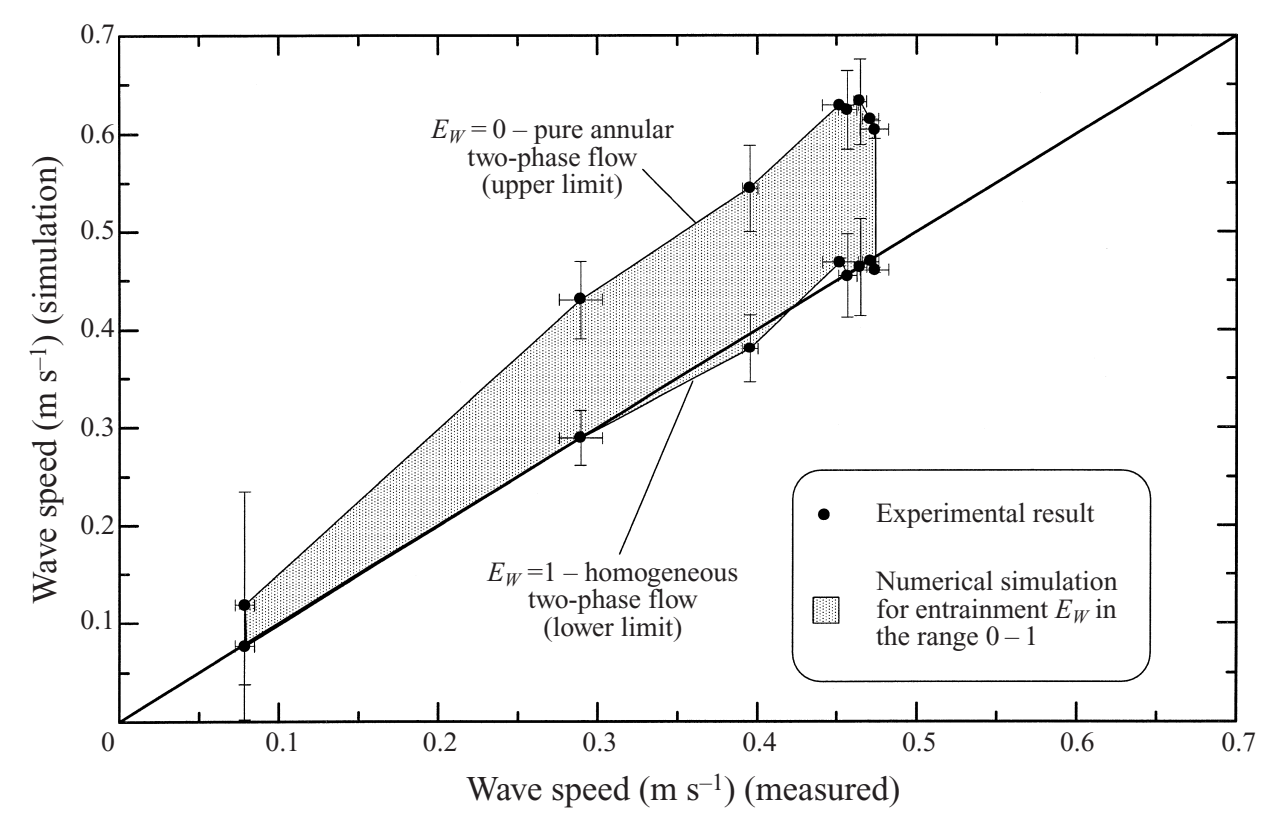

FIGURE 11. Comparisons of the numerical solution of the CJ wave speed with the measured values for the isothermal series of tests (see table 3).

hand, wave speeds (figure 11) were predicted reasonably well by the homogeneous model for the isothermal series of tests. A possible explanation for the differences in the numerical results may be related to the trend of the wave speed vs. downstream pressure curves (figure 7). The inclination of the subsonic branch (to the right of the 


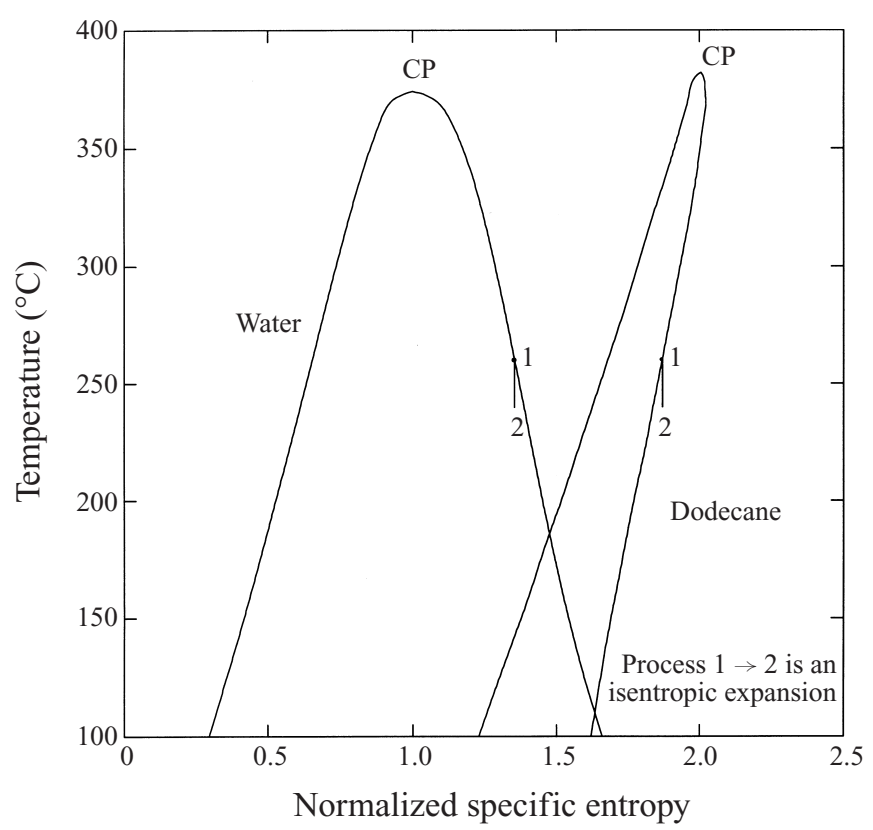

FIGURE 12. Temperature-entropy diagrams of: $(a)$ regular substance (water); $(b)$ retrograde substance (dodecane). CP denotes the critical point.

CJ point) is quite steep and a small perturbation in measured pressure value will result in a large change in wave speed.

\section{Complete evaporation waves}

The form of (13) suggests the possibility of complete evaporation waves, i.e. a vapour quality $x$ of unity. This possibility is intimately related to the thermodynamic behaviour of the fluid, in particular the characteristics of the saturation properties. Visual inspection of the saturation dome in the temperature-entropy plane (figure 12) suggests that as the molecular complexity, i.e. the number of atoms per molecule, increases, the saturation region tilts to the right. A substance such as dodecane with a characteristic saturation curve of the type illustrated on the right of figure 12 is referred to as retrograde. The vague term regular is used to classify substances like water with a characteristic saturation dome of the type shown on the left of figure 12. The retrograde property is precisely that the slope of the vapour saturation line is positive,

$$
\left.\frac{\mathrm{d} S}{\mathrm{~d} T}\right|_{\sigma, V}>0,
$$

where the subscript $\sigma, V$ refers to the saturated vapour line.

Retrograde and regular fluids are distinguished by the qualitative differences in behaviour during an adiabatic process, see figure 12. Regular fluids evaporate when a liquid-vapour mixture is adiabatically compressed $(2 \rightarrow 1)$, while retrograde fluids evaporate when adiabatically expanded $(1 \rightarrow 2)$.

From the geometry of the $T-S$ diagram it is apparent that if a fluid is sufficiently retrograde, complete adiabatic phase change is possible (Thompson \& Sullivan 1975). Physically, this occurs when the amount of energy stored in the intramolecular degrees 
of freedom is comparable to, or greater than, the intermolecular attraction that is the origin of the enthalpy of vapourization. In other words, a fluid is retrograde when the number of atoms and the associated vibrational degrees of freedom are sufficiently high. A dimensionless heat capacity may be defined (Thompson \& Sullivan 1975) to characterize retrograde behaviour:

$$
\tilde{C}_{v}=\frac{C_{v}^{0}\left(T_{c}\right)}{\tilde{R}},
$$

where $C_{v}^{0}\left(T_{c}\right)$ is the ideal gas heat capacity at constant volume at the critical point and $\tilde{R}$ the universal gas constant. The higher $\tilde{C}_{v}$, the more pronounced the retrograde behaviour. Thompson \& Sullivan (1975) found that retrograde behaviour is possible for $\tilde{C}_{v}>11$ and a complete adiabatic liquefaction (Dettleff et al. 1979) is possible for $\tilde{C}_{v}>24$. For adiabatic evaporation waves, complete evaporation (Shepherd et al. 1990) can occur for $\tilde{C}_{v}>33$. Dodecane has a value of $\tilde{C}_{v} \approx 60.4$.

One of the goals of the present study was the possibility of experimentally observing complete evaporation waves in a one-dimensional geometry. Previous experimental studies (Chaves et al. 1985; Hill 1991) in confined flows have resulted only in twophase downstream states. Kurschat, Chaves \& Meier (1992) were able to obtain complete evaporation when they allowed highly-superheated liquid to expand radially as a supersonic jet in a low-pressure chamber. We believe that there is no fundamental reason why one-dimensional complete evaporation waves cannot occur within a confined tube-like geometry also. Our computations indicate that if the initial and final conditions and a suitable fluid are carefully selected, complete evaporation is possible.

An experimental investigation of complete evaporation waves in constant-area one-dimensional flow presents special problems. Several constraints must be satisfied:

(i) The fluid must have sufficient molecular complexity, i.e. the parameter $\tilde{C}_{v}$ must be large enough $\left(\tilde{C}_{v}>33\right.$, for instance).

(ii) The amount of superheat must be sufficiently large to store enough energy in the molecules to supply the latent heat of evaporation, i.e. the Jakob number must be greater than one, where $J a=C_{p} \Delta T / h_{L V}$.

(iii) The degree of superheat cannot be too high since explosive boiling will occur if $T$ is higher than about $90 \%$ of the critical temperature.

(iv) The surface finish and interfacial properties must be chosen to suppress nucleation.

Conditions (i) and (ii) are fundamentally questions of thermodynamic properties of the test fluid. It has been estimated (Shepherd et al. 1990) that octane, $\mathrm{C}_{8} \mathrm{H}_{18}$, is the simplest fluid for which complete evaporation would be possible. However, the calculations in Shepherd et al. (1990) indicated that octane is not a practical choice for experiments since a large superheat is required, violating condition (iii) Further study (Simões-Moreira et al. 1993) of this issue determined that dodecane was a more practical choice. Figures 13 and 14 show the results of direct and inverse evaporation adiabat computations which demonstrate the potential for complete evaporation waves.

There exists a range of metastable states that will result in pure vapour downstream states, that is, evaporation waves with upstream states inside such regions would result in a downstream state of vapour. These regions are shown shaded in figures 13-15. The left side of the shaded region is bounded by the minimum degree of metastability that would give a dry saturated vapour downstream. The right boundary is the liquid spinodal line. 


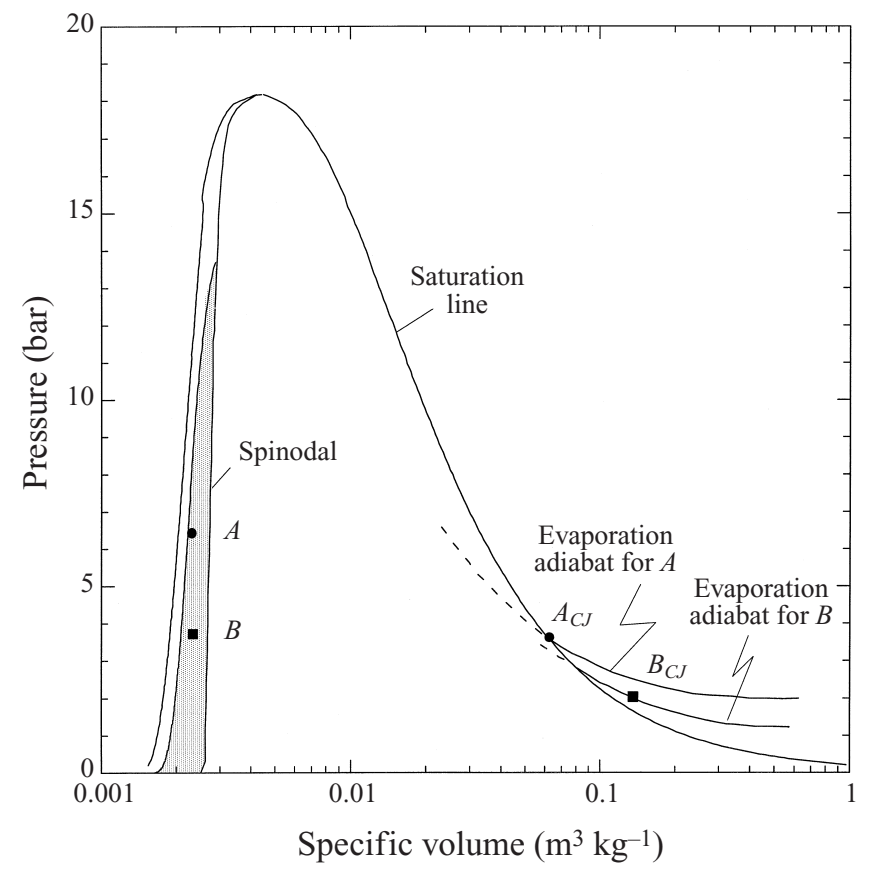

FIGURE 13. Pressure-volume diagram with two representative starting states and the resulting evaporation adiabats for superheated dodecane. Initial conditions which result in complete evaporation are shown as the shaded region.

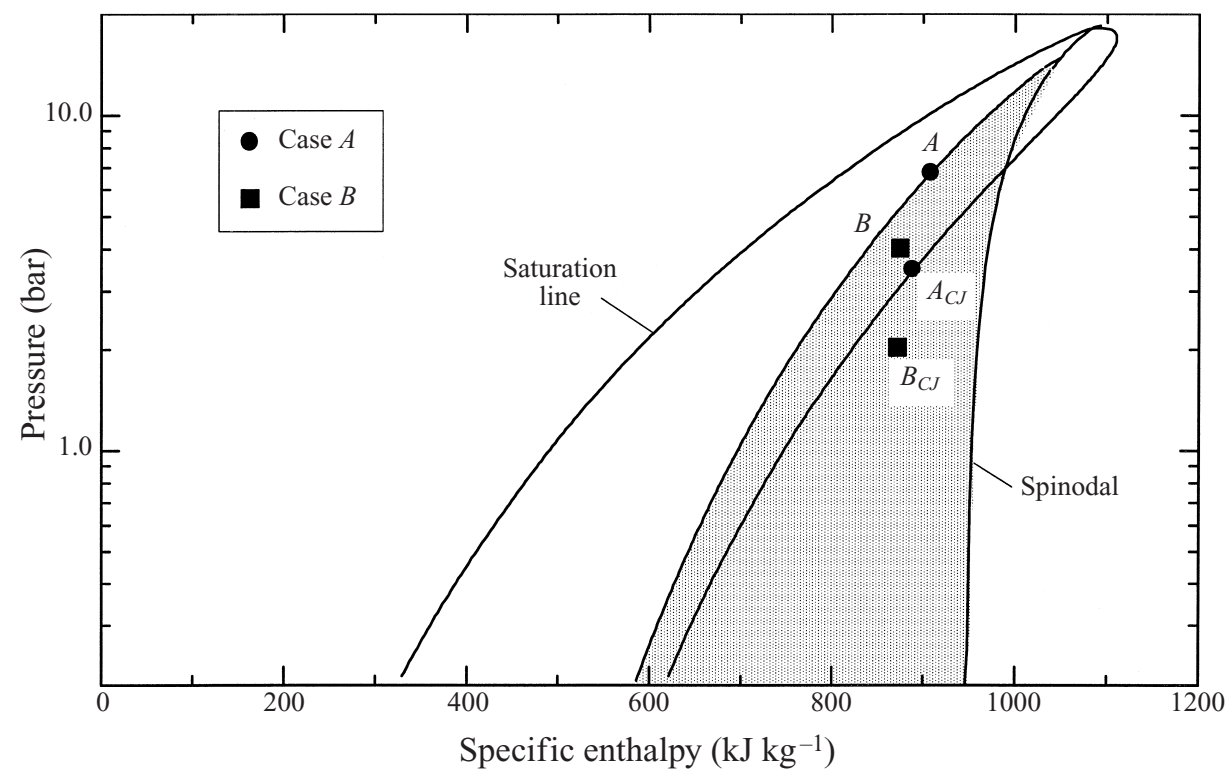

FIGURE 14. Enthalpy-pressure diagram with two representative starting states and the resulting evaporation adiabats for superheated dodecane. Initial conditions which result in complete evaporation are shown as the shaded region. 
Evaporation waves in superheated dodecane

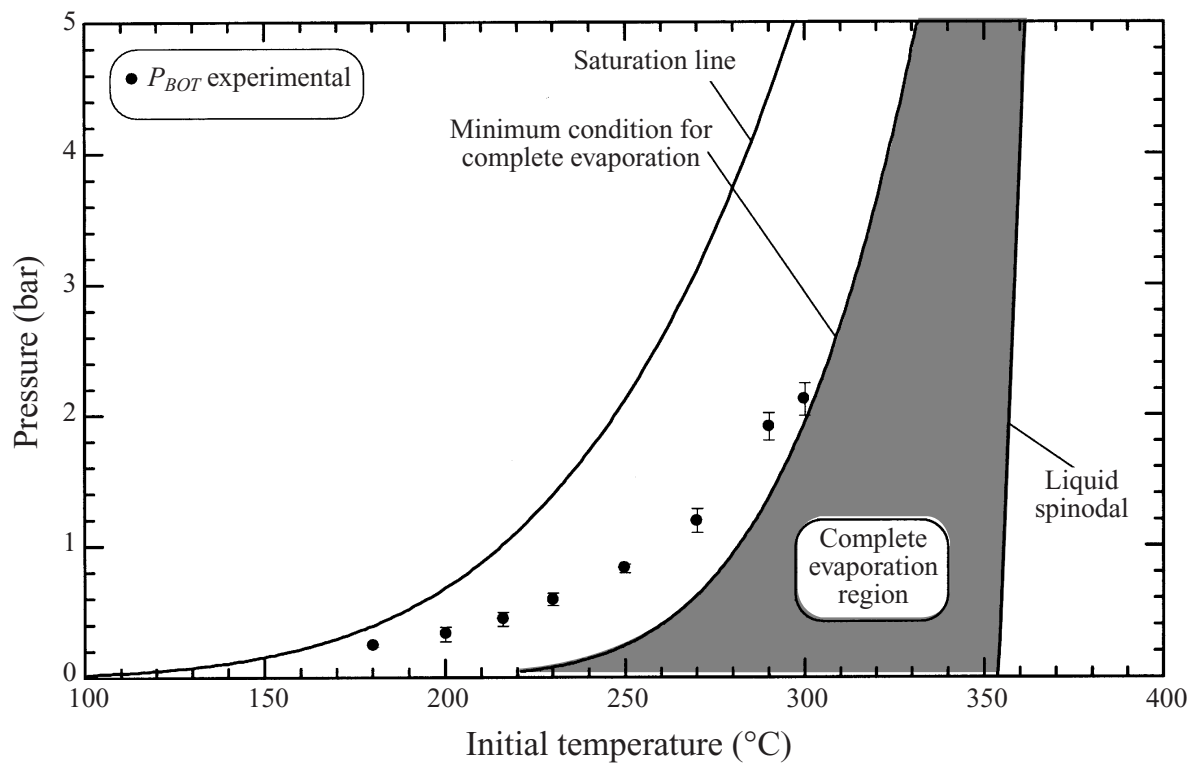

FIGURE 15. Comparisons of the metastable pressure reached in the experiments and the criteria for complete evaporation of Simões-Moreira et al. (1993).

(a)

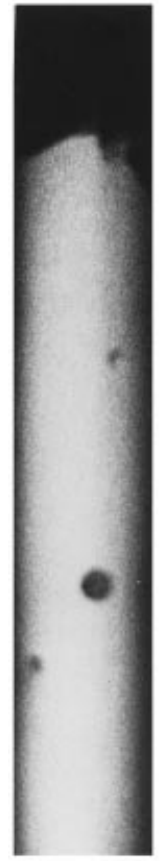

(b)

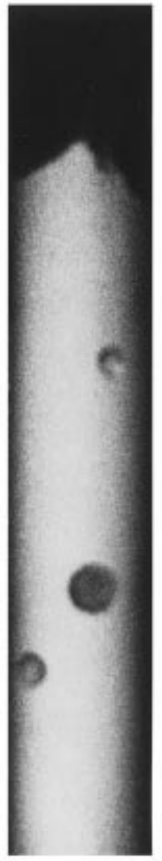

(c)

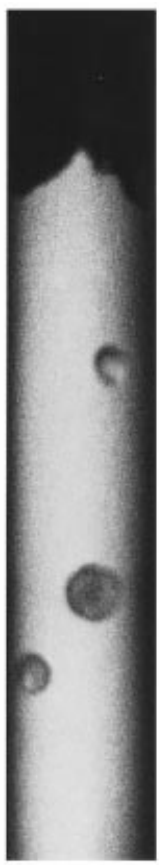

$(d)$

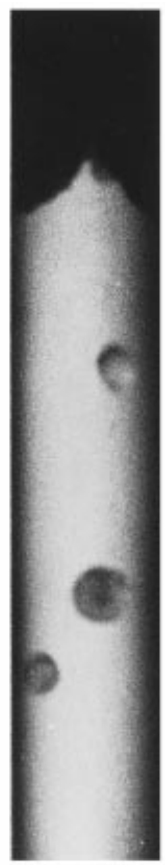

(e)

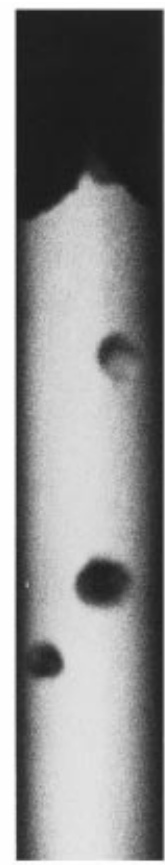

$(f)$

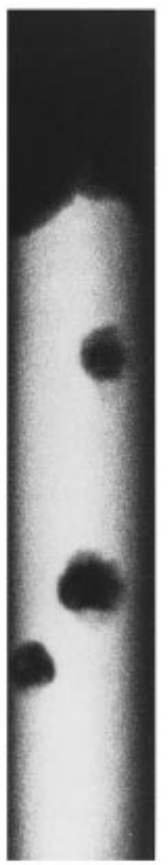

FiguRE 16. Selected frames from test dd-f-48, performed at $315^{\circ} \mathrm{C}$, the highest temperature in our tests. Multiple nucleation sites within the liquid are visible. Frames are approximately $0.33 \mathrm{~ms}$ apart in time. 


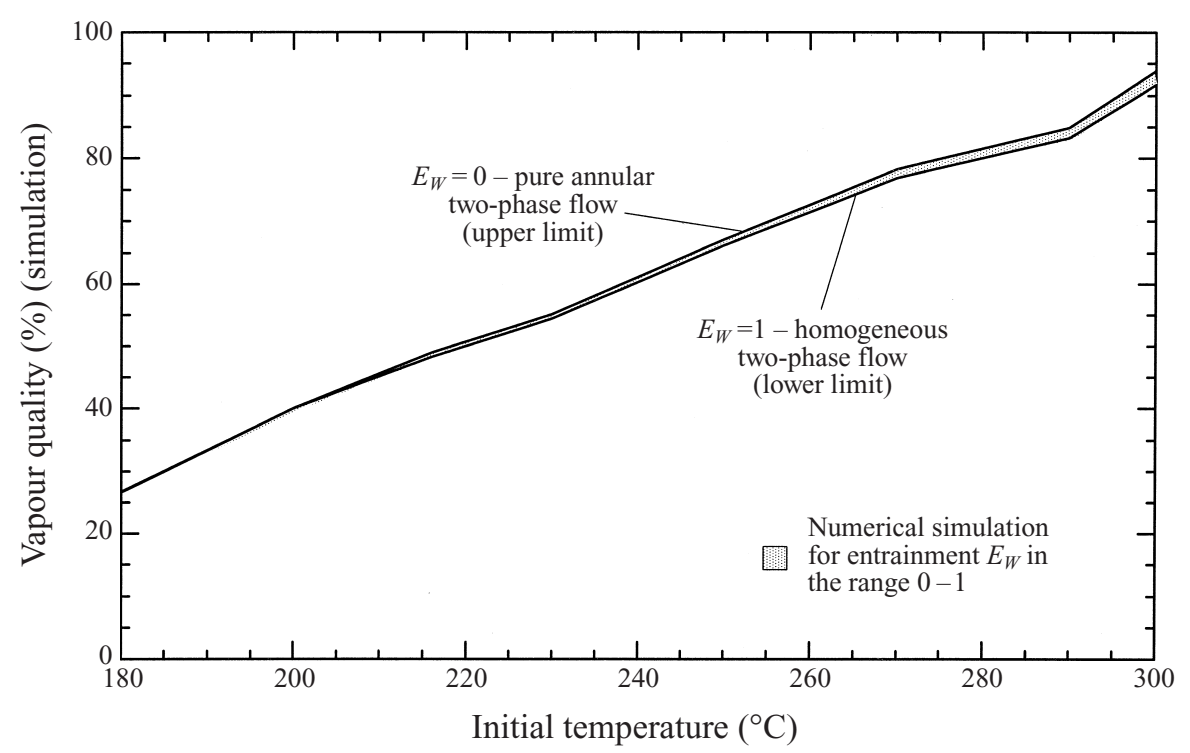

FIGURE 17. Estimated mass vapour quality $x$ as function of initial temperature.

Our experimental results are shown in figure 15. As the initial liquid temperature was increased, complete evaporation was approached but was not actually obtained. Extrapolating the experimental trend, a complete evaporation wave would be anticipated in the temperature range of $310-320^{\circ} \mathrm{C}$. Two trials were done at $315^{\circ} \mathrm{C}$ and both resulted in nucleation either within the fluid or at the test cell wall upstream of the liquid-vapour interface. Photographic evidence of this behaviour is shown in figure 16. Based on our thermodynamic computations, we had expected to be able to reach the complete evaporation condition at much lower superheats. However, the unexpected increase of the liquid pressure prevented us from attaining the predicted superheats. We attribute the increase in pressure to flow losses within the exit section of the apparatus due to the very non-ideal configuration of the connection to the low-pressure reservoir (see figure 3).

In the present experiments, vapour quality was not directly measured but could be estimated from solutions to the jump conditions. The estimated vapour quality $x$ for the choked test series, figure 17, confirms the approach toward complete evaporation as the initial temperature increased. The difference between the two models is much less pronounced for the vapour quality than for the evaporation wave velocity and downstream pressure (figures 9 and 10). The estimated vapour quality at $180^{\circ} \mathrm{C}$ is nearly $27 \%$ for both models and $91-94 \%$ at $T=300^{\circ} \mathrm{C}$. In agreement with the previous analysis on minimum metastable pressure (figure 15), it is predicted that complete evaporation $(x=1)$ would occur between 310 and $320^{\circ} \mathrm{C}$.

\section{Conclusions}

Our experiments have extended previous work on evaporation waves to a highly retrograde material, dodecane. At modest superheats, we have obtained results similar to previous studies with regular fluids. We have systematically explored the effect of downstream conditions and have shown how a maximum mass flux condition is approached as the superheat is increased. Comparisons of the experiments to a 
simple control-volume model reveal that the flow is best simulated as an annular two-phase flow with some degree of liquid entrainment.

We fell short of the most ambitious goal of our project, which was to obtain complete evaporation waves. Although we were able to obtain a downstream state that we estimate to be over $90 \%$ vapour, nucleation prevented attaining a sufficiently superheated upstream state. Our computations and the trends of the experimental data do not indicate that there are any fundamental barriers to obtaining a complete evaporation wave.

The mechanism of the evaporation front instability and propagation still remains to be clarified. Our observations are very similar to Hill's and strongly suggest a universal mechanism that causes a very frothy front with bursts of droplets being flung into the flow. However, the spatial and temporal resolution is not sufficient to distinguish if nucleation occurs within the front or if a more subtle instability is operating.

The first author thanks CNPq, Conselho Nacional de Desenvolvimento Cientifico e Tecnológico, Brazil, for the financial support and the Department of Mechanical Engineering of Escola Politécnica da Universidade de São Paulo, Brazil, for granting him a leave of absence. This research was carried out at the Graduate Aeronautical Laboratory of the California Institute of Technology and supported by the Powell fund at Caltech. Both authors would like to acknowledge the importance of the ideas of Philip A. Thompson. Philip's vision of compressible fluid dynamics and deep insight into the role of thermodynamics in these flows have had a profound influence on us.

\section{REFERENCES}

Chaves, H. 1984 Phasenübergänge und Wellen bei der Entspannung von Fluiden hoher spezifischer Wärme. Dissertation, Georg August Universität, Göttingen.

Chaves, H., Lang, H., Meier, G. E. A. \& Speckman, H. D. 1985 Adiabatic phase transition and wave splitting in fluids of high specific heat. In Flow of Real Fluids (ed. G. E. Meier \& P. A. Thompson). Springer.

DAS, P. K., Bhat, G. S. \& ARAKERI, V. H. 1987 Investigations on the propagation of rapid depressurization of subcooled liquid. Intl J. Heat Mass Transfer 6, 975-984.

Dettleff, G., Thompson, P. A., Meier, G. E. A. \& Speckmann, H. D. 1979 An experimental study of liquefaction shock waves. J. Fluid Mech. 95, 279-304.

Fauske, H. K. 1962 Contribution to the theory of two-phase, one-component critical flow. Argonne National Laboratory Rep. ANL-6633.

Frost, D. 1988 Dynamics of explosive boiling of a droplet. Phys. Fluids 31, 2554-2561.

Frost, D. \& Sturtevant, B. 1986 Effects of ambient pressure on the instability of liquid boiling explosively at the superheat limit. Trans. ASME, 108, 418-424.

Grolmes, M. A. \& Fauske, H. K. 1974 Axial propagation of free surface boiling into superheated liquids in vertical tubes. Proc. 5th Intl Heat Transfer Conf. (Tokyo), Vol. IV, pp. 30-34. The Japan Society of Mechanical Engineers.

Hewitt, G. F. \& Hall-Taylor, N. S. 1970 Annular Two-Phase Flow. Pergamon.

HiLl, L. G. 1991 An experimental study of evaporation waves in a superheated liquid. PhD thesis, California Institute of Technology, Pasadena, CA.

Hill, L. G. \& Sturtevant, B. 1990 An experimental study of evaporation waves in a superheated liquid. In Adiabatic Waves in Liquid-Vapor Systems (ed. G. E. A. Meier \& P. A. Thompson), pp. 25-37. Springer.

Kurschat, Th., Chaves, H. \& Meier, G. E. A. 1992 Complete adiabatic evaporation of highly superheated liquid jets. J. Fluid Mech. 236, 43-59.

Labuntsov, D. A. \& AvdeEv, A. A. 1981 Theory of boiling discontinuity. Teplofizika Vysokikh Temperatur 19, 552-556. 
Labuntsov, D. A. \& Avdeev, A. A. 1982 Mechanism of flow blockage involving shock boiling of liquids. Teplofizika Vysokikh Temperatur 20, 88-95.

LeE, B. I. \& KesLeR, M. G. 1975 A generalized thermodynamic correlation based on three-parameter corresponding states. AIChE J. 21, 510-527.

McCahan, S. M. 1992 Thermodynamic applications: rapid evaporation and reacting flow. PhD. thesis, Rensselaer Polytechnic Institute, Troy, NY.

McCahan, S. \& ShePherd, J. E. 1993 Models of rapid evaporation in nonequilibrium mixtures of tin and water. Prog. Astronaut. Aeronaut. 154, 432-448.

Nguyen, V. T., Furzeland, R. M. \& IJpelaAR, M. J. M. 1988 Rapid evaporation at the superheat limit. Intl J. Heat Mass Transfer 31, 1687-1700.

ReID, R. C. 1976 Superheated liquids. American Scientist 64, 146.

ReID, R. C. 1983 Rapid phase transition from liquid to vapor. Adv. Chem. Engng 12, 105.

Reid, R. C., Prausnitz, J. M. \& Poling, B. E. 1987 The Properties of Gases and Liquids, 4th Edn. McGraw-Hill.

Shepherd, J. E., McCahan. S. \& Cho, J. 1990 Evaporation wave model for superheated liquids. In Adiabatic Waves in Liquid-Vapor Systems (ed. G. E. A. Meier \& P. A. Thompson), pp. 3-12. Springer.

Shepherd, J. E. \& Sturtevant, B. 1982 Rapid evaporation at the superheat limit. J. Fluid Mech. 121, 379-402.

Simões-Moreira, J. R. 1994 Adiabatic evaporation waves. PhD thesis, Rensselaer Polytechnic Institute, Troy, NY.

Simões-Moreira, J. R., McCahan, S. \& Shepherd, J. E. 1993 Complete evaporation waves. Presented at ASME Fluid Engineering Conference, Paper 93-FE-7 ASME, Washington, DC.

Simões-Moreira, J. R. \& Shepherd, J. E. 1994 Adiabatic evaporation waves. J. Brazilian Soc. Mech. Sci. XVI(4), 445-451.

Terner, E. 1962 Shock-tube experiments involving phase changes. Indust. Engng Chem. Process Design Dev. 1, 84-86.

Thompson, P. A. 1972 Compressible Fluid Dynamics, pp. 347-352. McGraw-Hill.

Thompson, P. A., Chaves, H., Meier, G. E. A., Kim, Y. G. \& Speckmann, H. D. 1987 Wave splitting in a fluid of large heat capacity. J. Fluid Mech. 185, 385-414.

Thompson, P. A. \& Sullivan, D. A. 1975 On the possibility of complete condensation shock waves in retrograde fluids. J. Fluid Mech. 70, 639-649.

Wallis, G. B. 1969 One-Dimensional Two-Phase Flow. McGraw-Hill. 